\title{
Yöneticilerin Kuantum Liderlik Algılarının İncelenmesi Üzerine Nitel Bir Araştırma
}

\section{Gözde $\mathrm{KOSA}^{1}$}

\section{$\ddot{O} z$}

$\mathrm{Bu}$ araştırmanın amac1, özel ve kamu sektöründe görev yapan üst düzey yöneticilerin kuantum liderlik algıları düzeylerini belirlemektir. Araştırma sonucunda elde edilen bulgulara göre, katılımcı yöneticilerin kuantum liderlik algılarının yüksek, olumlu yönde olduğu ve önemsedikleri görülmüştür. Katılımcıların cinsiyet ve çalıştıkları kurum türüne göre (özel-devlet) kuantum liderlik algıları benzer düzeydedir. Bununla birlikte mesleki kıdem arttıkça katılımcıların kuantum liderlik algılarının yükseldiği belirlenmiştir. Araştırmanın nitel bulgularına göre katılımcıların “yönetim ve liderlik konusundaki eğitimlere yoğun katılım gösterdikleri görülmüştür. Bu kapsamda katılımcıların eğitimlere, liderlik eğitimi programlarına, gelişim programlarına, yöneticilik eğitimlerine, üniversite konferans ve seminerleri, şirket içi çalışmalar ve toplantılara kapsamındaki liderlik programlarına katıldıkları belirlenmiştir. Araştırmanın nitel bulgularına göre, katılımcıların çok azının liderlik kavramını bilimsel ve teknik terminolojiye göre tanımladığı buna karşın çoğunun ise kısa anonim hale gelmiş özdeyişlerle kendi kişisel görüşlerine göre bir liderlik tanımlamasına sahip olduğu gözlenmiştir. Katılımcı görüşlerine göre yöneticilerin çalıştıkları kurumlarında, kaotikbelirsiz liderlik yaklaşımı yerine, belirsizlik durumlarında, iletişim odaklı ve sorun çözümüne yönelik kuantum liderlik yaklaşımının ön plana çıktı̆̆ı görülmüştür. Çalışmanın bulguları, özel ve kamu kurum yöneticilerinin kurumlarında kuantum liderlik davranışlarını olumlu yönde geliştirmeye yönelik beklentilerinin güçlü olduğunu ortaya çıkarmıştır.

Anabtar Kelimeler: Kuantum Liderlik, Yöneticiler, Nitelik Analizi

\section{A Qualitative Research on Examination of Quantum Leaders 'Perceptions of Executives}

\section{Abstract}

The aim of this study is to determine the level of quantum leadership perceptions of senior executives in private and public sector. The research was conducted in a qualitative design. According to the findings of the research, it was seen that the quantum leadership perceptions of the participant managers were high, positive and important. According to the qualitative findings of the study, it was observed that the participants took an active part in trainings on management and leadership. In this context, they attended trainings, leadership training programs, development programs, management trainings, university conferences and seminars, in-house studies and meetings. According to the qualitative findings of the study, it was observed that few of the participants defined the concept of leadership according to scientific and technical terminology, whereas most of them had a definition of leadership according to their personal opinions with short anonymized statement. According to the participants' opinions, instead of chaotic-uncertain leadership approach, it is seen that communication-oriented and problem-solving quantum leadership approach comes to the forefront in uncertain situations. The findings of the study revealed that the expectations of private and public sector managers to develop quantum leadership behaviors positively in their institutions were strong.

Key Words: Quantum Leadership, Managers, Quantitative Analysis

Atıf İçin / Please Cite As:

Kosa, G. (2020). Yöneticilerin kuantum liderlik algılarının incelenmesi üzerine nitel bir araştırma. Manas Sosyal Arastırmalar Dergisi, 9(2), 916-926.

Geliş Tarihi / Received Date: 18.04.2019

Kabul Tarihi / Accepted Date: 09.09.2019 


\section{Giriş}

Günümüz yönetim anlayışında, örgütler dinamik sistemler olarak işlev gören karmaşık yapılardır. Örgütlerin en temel en öğesinin insan faktörü olması, insan öğesinin de örgüt amaçlarına katkısını arttırabilmek adına beklentilerinin karşılanması gerekliliği örgütlerde etkin bir yönetim yapısını ve liderliği zorunlu kılmaktadır. Yönetimde kuantum görüşü, bir organizasyonu ve üyelerini işbirliği ve etkileşim ile güçlendirilmiş, birbirine bağl1 enerjik varlıklar olarak görmektedir. Bu bağlantılar doğrusal ve hiyerarşik değildir. Örgütlerde Kuantum perspektifi ise etkileşimi ve tüm üyeleri de etkiler (Quigley, 1997, s. 44). Kuantum perspektifi, örgütlerde etkileşimin ortak amaçlar ve açık ve etkili iletişimle çalışanlar arasında ortaya çıktığını göstermektedir. Bu kapsamda örgütlerde, çalışanların ve iş yaşamında olumlu bir fark yaratabilmek için ortak amaçlarla doğrultusunda hareket etmeyi destekleyen liderlik yaklaşımları gerekmektedir. Kuantum liderlik, sahip olduğu özelliklerle basit bir postmodern teori değildir. Yeni bir paradigmadır. Kuantum liderliğinin hüküm sürdüğü örgüt ortamlarında genellikle belirsizlik durumu hâkimdir. Belirsizlik durumunun getirdiği düzensizlik ve karmaşıklık durumu söz konusudur. Örgütlerde belirsizlik durumunun hâkim olduğu durumlarda kuantum liderler belirlenen ortak hedefe ulaşmada çalışanları harekete geçirmektedir.

Treichler ve Carmichael'e göre (2004) Kuantum liderlik yaklaşımını benimseyen örgütlerde, liderler örgütün misyonu ve vizyonuna göre yönetim stratejileri belirlemekte, çalsşanlar arasında uyum ve işbirliği gelişmesine katkı sağlamaktadırlar. Kuantum liderlik yaklaşımı, hem bireyleri hem de kuruluşları belirlenen vizyon, misyon ve hedefler doğrultusunda iki yönlü açık iletişimle güçlü ilişkiler kurma, üyeleri dinleyerek ve güçlendirerek bilgi edinerek bilinçli bir yönetim anlayışını içermektedir (Youngblood, 1997, s. 8). Kuantum liderlik, organizasyonu geleceğe yönlendiren ve hedeflerine ulaştıracak bilinçle gelecekteki verimlilik, performans ve karlılık ve rekabet avantajı sağlaması açısından son derece önemlidir (Kilmann, 2001, s. 42). Kuantum liderlik, örgütsel bir görev değildir, ancak tüm çalışanların örgütteki işleyişe aktif katılımını sağlayan bir süreçtir. Kuantum örgütlerde, liderler gücünü bağlı çalışanlara devrederler (Jacobs, 1994, s. 4). Liderler kuantum bilinciyle, sezgisel süreçle doğru yönetim anlayışı belirlemek için sürekli öğrenmeyi destekleyici tüm çalışanları kapsayacak bir yapı oluşturmak isterler (Rose ve Nicholl, 1997, s. 62). Liderler kuantum becerilerini kendileri ve organizasyon amaçlarını planlamak için kullanırlar. Liderler tarafindan bu beceriyi kullanmak, nezaket, şefkat ve dürüstlük davranışlarının tüm organizasyon genelinde kabul görmesini sağlamaktadır (Zohar, 1991, s. 51). Kuantum becerilerini kullanmak, geleneksel organizasyondaki geleneksel yapılar nedeniyle oldukça zor bir süreçtir. Kuantum liderlik birçok yeni örgütsel süreç yaratmakta ve çalışanın örgüt amaçlarına katkı sağlamasını büyük ölçüde kolaylaştırmaktadır (Owen, 1997, s. 23). Liderler kuantum yeteneklerini organizasyonlarında uygulamak için çalışanlarının birbirleriyle herhangi bir kısıtlama olmadan ve yatay ve dikey organizasyon yapısılya iletişim kurabilecekleri yeni bir ortam yaratmalıdırlar (Kilmann, 2011, s. 41).

Bu araştırmanın amac1, özel ve kamu sektöründe görev yapan üst düzey yöneticilerin kuantum liderlik algılarını belirlemektir. Kuantum liderlik, diğer liderlik tiplerinden farklı olarak örgütlerde belirsizlik durumlarında kestirilemeyen sonuçlar yarattığından, araştırma sorularının oluşturulmasında öncelikle kuantum liderlik yaklaşımının özelliklerinin ve yöneticilerin sahip olması gereken yeteneklerin belirlenebilmesi için alan yazın çalışması yapılmıştır. Yöneticilerin kuantum liderlik becerilerine sahip olup olmadıklarının belirlenmesi için kendilerine kuantum liderlerin taşıması gereken özellikler ile ilgili görüşme formunda yer alan sorular yöneltilmiştir. Araştırmanın katılımcılarını Kars ilinde görev yapan Özel ve Kamu sektöründe çalışan 30 üst düzey yönetici oluşturmuştur.

\section{Literatür Taraması}

\section{Kuantum Liderlik Kavramı ve Özellikleri}

Kuantum liderlik, belirsizlik durumunu örgüt ortamında anlamış, kabul etmiş ve planlarını ona göre yapan liderlik yaklaşımıdır. Bu durum, kuantum liderliğe daha nesnel bir tanımlama getirmeyi zorlaştırmaktadır. Çünkü diğer liderlik yaklaşımlarında olduğu gibi kuantum liderlik için bir kalıp oluşturmak ya da bazı özelliklerini ifade etmek zor hale gelmektedir. Erçetin'e (2000) göre, kuantum liderlik yaklaşımı, liderliği belirsiz, kestirilemeyen ve tanımsız "nondeterministik" bir gerçeklik olarak kabul etmektedir. Ancak Erçetin ve Kamacı (2008) bir karşılaştırma ile kuantum liderliğin diğer liderlik yaklaşımlarından olan farkını anlatmaktadır. Buna göre klasik fizik ilkelerine dayalı olarak ortaya konulan liderlik yaklaşımları, liderin özelliklerinden doğan, nedensellikle açıllanan, kişisel güce bağlı olan, sürekli bir özelliktir. Kuantum kuramına dayalı liderlikte, lider-üye etkileşiminden doğan, nedensellikle tahmin 
edilmesi mümkün olmayan, etkisi kişiler arasındaki etkileşimlere bağlı, kesikli bir özelliktir (Ertürk, 2016, s. 166).

Kuantum teorisine göre, liderleri zihinsel modellerini inceleyebilecek ve böylece öğrenme kapasitelerini artıracak yedi kuantum beceri vardır.

Tablo 1. Kuantum Liderlik Becerileri

\begin{tabular}{cll}
\hline Kuantum Liderlik Becerileri & \\
\hline Beceri & & Yetenek \\
1. & Kuantum Görmek & Bilerek görme yeteneği \\
2. Kuantum Düşünme & Yaratıcı problem çözme yeteneği \\
3. Kuantum Duygu & Aktif olarak hissetme yeteneği \\
4. Kuantum Biliş & Sezgisel olarak tanıma becerisi \\
5. Kuantum Davranış & Hesap verebilir şekilde davranma becerisi \\
6. Kuantum Güven & Yaşam sürecine güvenme yeteneği \\
7. & Kuantum Oluş & Birlikte olma becerisi \\
\hline
\end{tabular}

(Shelton, 2011, s. 9)

Yeni bilim olarak da adlandırılan kuantum mekaniği birçok alanda olduğu gibi örgüt ve yönetim alanında da etkili olmuştur. Araştırmacılar kuantum fiziğinin temel varsayımlarından yola çıkarak örgütsel yap1 ve işleyişe ilişkin yeni modeller tasarlamış, kuantum örgüt, kuantum davranış, kuantum yapı ve nihayet yönetim alanında kuantum liderlik kavramları ortaya çıkmışır. Uzunçarşıll, Toprak ve Ersun'a göre (2000) kuantum liderlik insan fiziğinin harekete geçirilmesi sürecidir. Kuantum fiziğinin en güçlü enerji seviyelerini açıklamasından yola çıkarak kuantum liderliği de izleyenlerdeki enerjiyi harekete geçiren, üretkenliği destekleyen ve belirsizliğin getirdiği yaratıcı potansiyeli ortaya çıkaran sezgisel bir süreç olarak tanımlamıştır (Turan ve Erçetin, 2017, s. 767). Erçetin (2000) ise kuantum liderlik özelliklerini belirleyebilmek için öncelikle kuantum liderlik varsayımlarını belirlemeye çalışmıştır. Bu varsayımları belirlemek için Erçetin, klasik fizik tarafindan şekillendirilen klasik liderlik varsayımlarına bakarak, kuantum fizik tarafından şekillendirilen kuantum liderlik varsayımlarını açıklamaya çalışışıı.

Tablo 2. Klasik ve Kuantum Firige Dayah Olarak Liderlik Varsaymlarn

\begin{tabular}{llll}
\hline \multicolumn{1}{c}{$\begin{array}{c}\text { Klasik Fizik } \\
\text { Varsayımları }\end{array}$} & $\begin{array}{c}\text { Klasik Fizik ve Liderlik } \\
\text { Varsayımları }\end{array}$ & \multicolumn{1}{c}{$\begin{array}{c}\text { Kuantum Fizik } \\
\text { Varsayımları }\end{array}$} & $\begin{array}{c}\text { Kuantum Fizik ve Liderlik } \\
\text { Varsayımları }\end{array}$ \\
\hline 1. Parça-dalga ayırımı & $\begin{array}{l}\text { 1. Liderlik, onu oluşturan } \\
\text { parçalardır }\end{array}$ & 1. Parça-dalga ikilemi & $\begin{array}{l}\text { 1. Liderlik lider-izleyenler } \\
\text { ikileminde bir etkileşim alanıdır }\end{array}$ \\
\hline $\begin{array}{l}\text { 2. Sebep-sonuç ilişkisi } \\
\text { ve kesinlikler }\end{array}$ & $\begin{array}{l}\text { 2. Liderlik sebep sonuç } \\
\text { mantığıyla açılanır }\end{array}$ & $\begin{array}{l}\text { 2. Belirsizlik ve } \\
\text { olasılıklar }\end{array}$ & $\begin{array}{l}\text { 2. Liderlik yapılandırılamaz ve } \\
\text { kestirilemez }\end{array}$ \\
\hline 3. Enerjinin sürekliliği & $\begin{array}{l}\text { 3. Liderlik bir kişiye } \\
\text { atfedilen sürekli bir }\end{array}$ & 3. Enerjinin kesikliliği & 3. Liderlik olgusunun kesikliliği \\
& Özelliktir & & \\
\hline $\begin{array}{l}\text { 4. Uygulanan kuvvet } \\
\text { kadar kazanılan ivme }\end{array}$ & $\begin{array}{l}\text { 4. Liderlik etkisi güce } \\
\text { dayalıdır }\end{array}$ & $\begin{array}{l}\text { 4. Kuvvetin belli bir } \\
\text { yere kadar uygulanması }\end{array}$ & $\begin{array}{l}\text { 4. Liderliğin etkisi etkileşime } \\
\text { dayalıdır }\end{array}$ \\
\hline
\end{tabular}

(Erçetin, 2000, s. 77)

Kuantum paradigmasına göre kuantum liderliğin, yapılan tanımlar ve açılamalar doğrultusunda çeşitli özellikleri olduğu söylenebilir. Kuantum liderlik süreç odaklı olma, ortak bir vizyon oluşturma, sinerji ve etkileşim yaratma, örgütsel çevreyi göz önünde bulundurma, işbirliği yapma, örgüt üyelerini destekleme, örgütsel ve bireysel ilgilere odaklanma, örgüt üyelerini potansiyel bir lider olarak görme, değişmeyen eve statükoya karşı olma, öğrenen lider olma, firsatları değerlendirme ve firsat oluşturma gibi özellikleri içinde barındıran bir liderlik türüdür (Erçetin, Çevik ve Çelik, 2018, s. 111).

Morrison'a göre (2002, s. 71) kuantum liderlik yaklaşımında liderin sahip olması gereken birtakım ayırt edici özellikler vardır. Liderlik yaklaşımında organizasyonda ortak bir vizyon oluşturmaktadır. Liderin organizasyondaki etkisi daha çok etkileşime bağlıdır. Liderliğin sonuçları önceden öngörülemez. Lider çalş̧anlar arasında iyi ilişkileri desteklemelidir. Lider belirsizlik durumlarında hızlı ve doğru karar verme yeteneğine sahip olmalıdır. Kuantum lider yukarıdaki özellikler kapsamında, organizasyondaki çalışanlar arasında açık iletişim sağlama, çalş̧anlara güven duygusu aşılama, ortak amaç ve vizyon doğrultusunda bir örgüt iklimi oluşturmalıdır. Ortak vizyonun kuantum liderlik yaklaşımının temeli olduğu yaklaşımından 
hareketle, liderin ortak değerlere sahip çıkılmasını sağlaması ortaya çıkabilecek olumsuz durumlar karşısında belirsizlik ortamıyla başa çıkılmasını kolaylaştıracaktır (Fris ve Lazaridou, 2006, s. 45).

\section{Yöntem}

Bu araştırmanın amacı, özel ve kamu sektöründe görev yapan üst düzey yöneticilerin kuantum liderlik algılarını belirlemektir. Araştırma sorularının oluşturulmasında öncelikle kuantum liderlik yaklaşımının özelliklerinin ve yöneticilerin sahip olması gereken yeteneklerin belirlenebilmesi için alan yazın çalışması yapılmış ve yöneticilerin kuantum liderlik becerilerine sahip olup olmadıklarının belirlenmesi için kendilerine görüşme formunda yer alan ifadeleri içeren sorular yöneltilmiştir.

Araştırma nitel desende oluşturulmuş ve yürütülmüştür. Nitel araştırmalarda gözlem, görüşme ve doküman analizi gibi nitel veri toplama yöntemleri kullanılır ve algılar ile olaylar doğal ortamda gerçekçi ve bütüncül bir biçimde ortaya konmaya çalışılır (Yıldırım ve Şimşek, 2005). Nitel araştırma kapsamında, görüşme formunun geçerliğini saptamak için yönetim organizasyon alanında çalışan iki profesör ve iki doçentten uzman görüşü alınmıştır. Uzmanların dönütlerine hazırlanan görüşme formuna gerekli alan yazın taramasının ardından son şekli verilmiştir. Araştırmada nitel verilerin geçerliğini sağlamak için uzman görüşlerine ve katılımcıların doğrudan alıntılarına yer verilmiştir (Yıldırım ve Şimşek, 2011). Araştırmanın katılımcılarını Kars ilinde görev yapan Özel ve Kamu sektöründe çalışan üst düzey 30 yönetici oluşturmaktadır. Katılımcıların yöneticilik pozisyonları Genel Müdür, Kurum Müdürleri, Şube Müdürleri, Daire Başkanları olarak yer almıştır. Katılımcıların demografik özelliklerine göre dağılımı Tablo 2'de yer almaktadır.

\section{Evren-Örneklem}

Araştırmanın katılımcılarını Kars ilinde görev yapan Özel ve Kamu sektöründe çalışan üst düzey 30 yönetici oluşturmaktadır. Katılımcıların yöneticilik pozisyonları Genel Müdür, Kurum Müdürleri, Şube Müdürleri, Daire Başkanları olarak yer almıştır.

\section{Veri Toplama Araçları}

Araştırmada veri toplama aracı olarak gerekli alan yazın taraması yapılmış toplam 19 sorudan oluşan görüşme formu kullanılmıştır. 4 soru ise açık uçlu içerik analizi yapılmak üzere katılımcılara sorulmuştur. Görüşme formunda yer alan sorular, kuantum liderlik yaklaşımının gerektirdiği özellikler göz önünde bulundurularak hazırlanmıştır. Görüşme yapılan üst düzey yöneticilerin görüşme sorularına verdikleri yanıtlar içerik analizi yöntemi kullanılarak değerlendirilmiştir.

\section{Verilerin Analizi}

Araştırmanın katılımcılarını Kars ilinde görev yapan Özel ve Kamu sektöründe çalışan 30 üst düzey yönetici oluşturmuştur. Katılımcıların demografik özelliklerine göre dağılımı Tablo 3 'te yer almaktadır.

Tablo 3. Katıllmcılarn Demografike Özelliklerine Göre Dağılımı

\begin{tabular}{llcc}
\hline & Değişken & $\mathbf{F}$ & $\mathbf{\%}$ \\
\hline \multirow{2}{*}{ Cinsiyet } & Erkek & 25 & 83,3 \\
& Kadın & 5 & 16,7 \\
\hline \multirow{4}{*}{ Ë̆itim durumu } & Ön lisans & 2 & 6,7 \\
& Lisans & 16 & 53,3 \\
& Yüksek lisans & 8 & 26,7 \\
& Doktora & 4 & 13,3 \\
\hline \multirow{2}{*}{ Çalışılan kurum } & Özel & 16 & 53,3 \\
& Kamu & 14 & 46,7 \\
\hline
\end{tabular}

Tablo incelendiğinde, katılımcıların \%83,3’ünün erkek, \%16,7'sinin ise kadın olduğu anlaşılmaktadır. Kat1lımc1ların eğitim durumuna göre incelendiğinde, \%6,7'sinin ön lisans, \%53,3’ünün lisans, \%26,7'sinin yüksek lisans ve \%13,3’ünün doktora mezunu olduğu anlaşılmaktadır. Katılımcıların \%53,3’ü özel kurumlarda, \%46,7’si ise kamu kurumlarında görev yapmaktadır. 
Tablo 4. Katılimclarn Yas, Çalısma Süresi ve Yöneticilike Görev Sürelerine Ait Betimsel Bilgiler

\begin{tabular}{llcccc}
\hline \multicolumn{1}{c}{ Değişken } & N & Minimum & Maksimum & $\overline{\boldsymbol{X}}$ & Ss \\
\hline Yaş & 30 & 25 & 55 & 37,77 & 8,19 \\
Çalışma süresi & 30 & 1 & 35 & 13,60 & 8,96 \\
Yöneticilik görev süresi & 30 & 1 & 15 & 5,27 & 4,11 \\
\hline
\end{tabular}

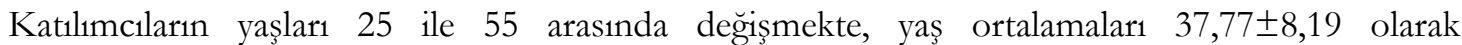
hesaplanmışır. Katılımcıların çalışma ve görev süreleri ise sırasıyla $1-35$ yıl ve $1-15$ yll arasında değişmektedir. Katılımcıların çalışma ve görev süresi ortalamaları ise sırasılyla $13,60 \pm 8,96$ ve $5,27 \pm 4,11$ olarak hesaplanmıştır

\section{Bulgular}

Tablo 5. Katılımolarm Kuantum Liderlik ile İlgili Iffadelere Vermiş Olduğu Cevaplarn Dağllımı

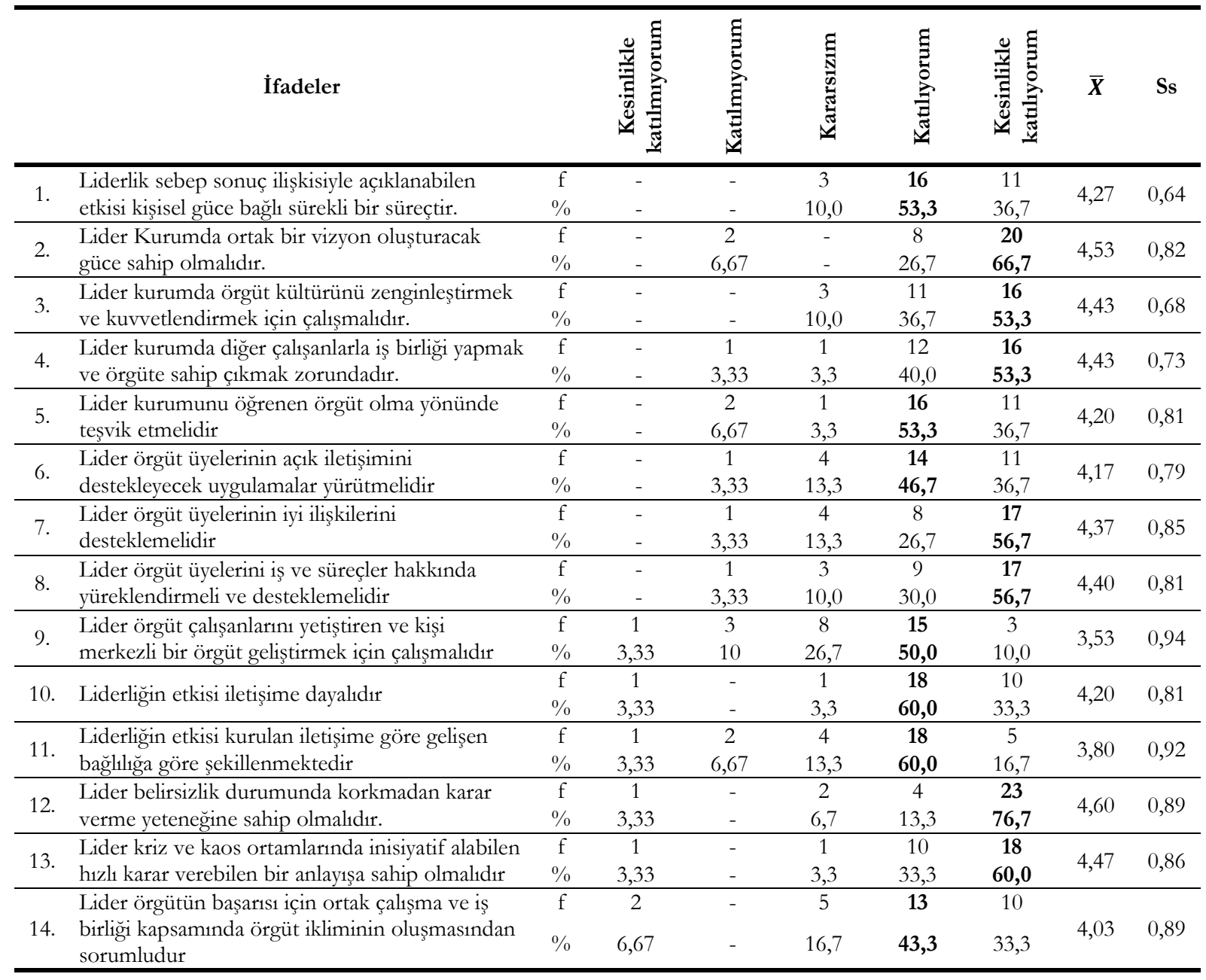

Tablo incelendiğinde, katılımcıların büyük bir oranının; "Liderlik sebep sonuç ilişkisiyle açıklanabilen etkisi kişisel güce bağlı sürekli bir süreçtir", "Lider kurumunu öğrenen örgüt olma yönünde teşvik etmelidir", "Lider örgüt üyelerinin açı iletişimini destekleyecek uygulamalar yürütmelidir", "Lider örgüt çalışanlarını yetiştiren ve kişi merkezli bir örgüt geliştirmek için çalışmalıdır", "Liderliğin etkisi iletişime dayalıdır", "Liderliğin etkisi kurulan iletişime göre gelişen bağlllı̆̆a göre şekillenmektedir" ve "Lider örgütün başarısı için ortak çalışma ve iş birliği kapsamında örgüt ikliminin oluşmasından sorumludur" ifadelerine katulyyorum şeklinde cevap vermiştir.

Katılımcıların büyük bir oranı; "Lider Kurumda ortak bir vizyon oluşturacak güce sahip olmalıdır", "Lider kurumda örgüt kültürünü zenginleştirmek ve kuvvetlendirmek için çalışmalıdır", "Lider kurumda diğer çalışanlarla iş birliği yapmak ve örgüte sahip çıkmak zorundadır", "Lider örgüt üyelerinin iyi ilişkilerini desteklemelidir", "Lider örgüt üyelerini iş ve süreçler hakkında yüreklendirmeli ve desteklemelidir", "Lider belirsizlik durumunda korkmadan karar verme yeteneğine sahip olmalıdır" ve 
"Lider kriz ve kaos ortamlarında inisiyatif alabilen hızlı karar verebilen bir anlayışa sahip olmalıdır" ifadelerine ise kesinlikle kathlyorum şeklinde cevap vermiştir.

Elde edilen sonuçlar, katılımcıların kuantum liderlik algılarının yüksek düzeyde olduğunu işaret etmiştir. Katılımcılar kuantum liderlik davranışlarını görev yaptıkları kurumlarda yoğun bir şekilde sergilediklerini düşünmektedir.

Tablo 6. Kuantum Liderlik Puanlarna Ait Betimsel Bilgiler

\begin{tabular}{cccccc}
\hline Değişken & N & Minimum & Maksimum & $\overline{\boldsymbol{X}}$ & Ss \\
\hline Kuantum liderlik puanları & 30 & 2,00 & 4,79 & 4,25 & 0,52 \\
\hline
\end{tabular}

Yönetici olarak görev yapan katılımcıların kuantum liderlik puanlarının 2 ile 4,79 arasında değiştiği anlaşılmaktadır. Kuantum liderlik puan ortalaması 4,25 $\pm 0,52$ olarak hesaplanmıştır. Elde edilen bu değer, araştırmaya katılan yöneticilerin kuantum liderlik algılarının yüksek olduğunu göstermektedir.

Tablo 7. Kuantum Liderlik Puanlarmın Cinsiyete Göre Karşılaștırılması

\begin{tabular}{|c|c|c|c|c|c|c|c|}
\hline Değişken & Cinsiyet & $\mathbf{N}$ & $\overline{\bar{X}}$ & Ss & $\mathbf{t}$ & Sd & $\mathrm{p}$ \\
\hline \multirow{2}{*}{ Kuantum liderlik alg1s1 } & Erkek & 25 & 4,23 & 0,55 & $-0,32$ & 28 & 0,75 \\
\hline & Kadin & 5 & 4,31 & 0,31 & & & \\
\hline
\end{tabular}

Tablo incelendiğinde, kuantum liderlik puanlarında cinsiyete bağlı anlamlı bir farklılığın bulunmadığı gözlenmiştir $(p>0,05)$. Kadın ve erkek yöneticilerin kuantum liderlik algılarının benzer düzeyde olduğu anlaşılmıştır.

Tablo 8. Katullmolarn Liderlik Yaklaşımlarn Konusundaki Bilgi Düzeyleri

\begin{tabular}{lcl}
\hline Bilgi Düzeyi & Frekans & Liderlik bilgilerinin nasıl edinildiği \\
\hline İyi & 13 & $\begin{array}{l}\text { Lisansüstü düzeyde liderlik eğitimine katılım } \\
\text { Liderlik programlarına katılım } \\
\text { Liderlik yaklaşımlarını yakından takip etmekteyim. }\end{array}$ \\
\hline Orta & 9 & $\begin{array}{l}\text { Üniversite yıllarından alınan eğitimlerle } \\
\text { Seminer, hizmet içi eğitim ve konferanslarla }\end{array}$ \\
\hline Düşük & 6 & Herhangi bir ders ya da programa katılım yok \\
\hline Bilgim yok & 2 & \\
\hline
\end{tabular}

Araştırmanın nitel boyutunda katılımclara kuantum liderlikle ilgili bilgi düzeyleri sorulmuştur. $\mathrm{Bu}$ soruya özel sektör yöneticilerinin 10'u iyi düzeyde, 6'sı orta düzeyde bilgisi vermiştir. Kamu sektöründeki yöneticilerin ise 6's1 iyi düzeyde,4'ü orta düzeyde, 2'si düşük düzeyde, 2'si ise bilgim yok şeklinde cevap vermiştir. Nitel analizlere göre liderlik konusunda bilgi düzeylerinin iyi olduğunu söyleyen katıllımcılar ağırlıklı olarak lisansüstü düzeyde liderlik eğitimi aldığını, liderlik eğitim programlarına katıldıklarını ve liderlik konusunu yakından takip ettiklerini söylemiştir. Bu soruya orta düzeyde bilgim var cevabını veren katılımcılar ise üniversite yıllarında aldıkları dersler ve kurumlarındaki konferans, seminer ve hizmet içi eğitimler vasıtasıyla liderlik hakkında bilgilere sahip olduklarını ifade etmişlerdir. Diğer taraftan liderlik bilgisi düşük ya da olmayan katılımcılar ise bu konuda herhangi bir eğitim ve programa katılmadıklarını ifade etmişlerdir.

Tablo 9. Katılımcılarn Yönetim ve Liderlik Konusunda Katıldı̆̆ı Ë̆itimler

\begin{tabular}{lllc}
\hline Katılım Durumu & Frekans & Eğitimlerin Niteliği & Frekans \\
\hline Hayır & 13 & & 5 \\
& & Kurum içi eğitimler & 4 \\
& & Liderlik eğitim programlarına katılım & 3 \\
& & Kişisel gelişim programları kapsamında eğitim & 3 \\
\multirow{2}{*}{ Evet } & \multirow{2}{*}{17} & Yöneticilik eğitimi kapsamında & 3 \\
& & Lisansüstü dersler kapsamında alınan eğitimler (TODAİE, Yüksek & 2 \\
& & Lisans ve Doktora dersleri) & 2 \\
& & Üniversite konferans ve seminerlerine katılım & 2 \\
\hline
\end{tabular}


Araştırma kapsamındaki katıllımcıların "Yönetim ve Liderlik konusunda katıldığı eğitimler" incelendiğinde 13 katılımcının 8'inin kamu sektör yöneticisi, 5’inin özel sektör yöneticisinin herhangi bir eğitim programına katılmadığı buna karşı 17 katılımcı içerisinde yer alan 5 kamu yöneticisinin sadece kurum içi eğitimlere katıldığı belirlenmiştir. Diğer 9 kamu yöneticisinin genel olarak en az bir programa katılım sağladığı görülmüsstür. Bu eğitimlerin nitelikleri incelendiğinde özel kurum yöneticilerinin kişisel gelişim programları, yöneticilik eğitimleri, lisansüstü dersler, üniversite konferans ve seminerleri, şirket içi çalışmalar ve toplantılar kapsamında liderlik programlarını aldıkları görülmüştür.

Tablo 10. Katılımalarn Liderlik Kavramına Ilisksin Yorumlar

\begin{tabular}{llll}
\hline Liderlik Yorumu & Frekans & Yorum şekli & Frekans \\
\hline Yorum yok & 5 & Bilimsel ve teknik terminoloji & 4 \\
Yorum var & 25 & Özdeyiş ve anonim sözler & 5 \\
& & Kişisel yorum & 11 \\
& & Yöneticilikle ilişkilendirerek yorumlama & 5 \\
\hline
\end{tabular}

Araştırma kapsamındaki katılımcıların "kendinize göre liderlik kavramını tanımlayınız" sorusuna vermiş oldukları cevaplar incelendiğinde 5 'inin bu soruya cevap vermediği diğer taraftan 25 'inin ise farklı içerik ve temalarla bu soruya cevaplar verdiği görülmüştür. Cevapların içerik analizine göre özel sektördeki yöneticilerden 9 katılımcının bilimsel ve teknik terminolojiye göre tanım yaptığı, 7 katılımcının klişeleşmiş kısa anonim hale gelmiş özdeyişlerle tanımla yaptığı görülmüştür. Kamu kurum yöneticilerinin 2 tanesi bilimsel ve teknik terminolojiye göre cevap vermiş, 7 katıllımc1 anonim cevaplar verirken, 5 katılımc1 soruyu yanıtsız bırakmıştır. Aşağıda bu soruya ilişkin katılımcıların ortaya koyduğu cevap ve görüşlere örnekler verilmiştir.

\section{K1: Bu konuyu 'Ya bir yol bul ya da bir yol yap' seklinde kusaca tanmlayabiliri:}

K2. Liderlik bana göre karşıdakini etkileme, gönül gücünü harekete geşirme becerisidir. Karşını̨̧a bulunan kitleyi

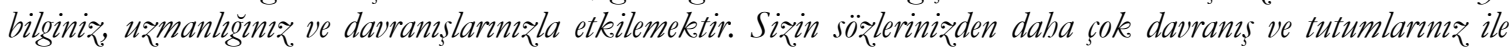

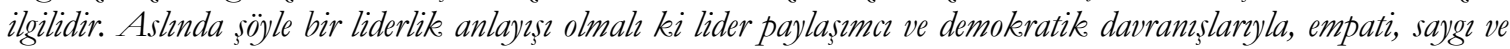
dürüstlïgü ile çevresini etkilemelidir.

K3: Astlarmmn fikirlerini dinleyen, bunun için ortam sağlayan, sorumluluklarmmn üstüne giden kişidir

K4: Liderlik; İçinde bulunulan örgütü ve üyelerini sürekli gelişim yönünde destekleyerek, örgüt içerinde yer alan bütün birim ve bireylerle iletişim ve dayanısma balinde çalssarak, inisiyatif alip motive ederek, bireyin doğuștan gelen pozitify yönlerini örgütün basan ve gelisimine kanalize ederek yürütülen bir süreştir.

Tablo 11. Katılimcilarn Görïslerine Göre Kurumlarnndaki Liderlik Tar₹̨lar

\begin{tabular}{ll}
\hline Kurumlardaki Liderlik Tarzları & Frekans \\
\hline Belirsiz-Kaotik & 1 \\
Liderlik yerine Yöneticilik & 6 \\
Bürokratik liderlik & 2 \\
İnsan Odakl1- Etkileşimli liderlik & 15 \\
İlgisiz liderlik yaklaşımı & 1 \\
Cevap yok & 5 \\
Toplam & 30 \\
\hline
\end{tabular}

Araştırma kapsamındaki katılımcıların "Kurumunuzda ki liderlik anlayışııı tanımlayınız:" sorusuna vermiş oldukları cevaplar liderlik yaklaşımları ve algıları açısından incelenmiş̧ir. Analizlere göre 1 yönetici kurumlarında kaotik-belirsiz liderlik olduğunu, 2 yönetici, katıllımcı bürokratik liderlik yaklaşımının baskın olduğunu, 15 kurum yöneticisi, insan odaklı ve etkileşimli liderlik yaklaşımının gözlemlendiğini, 1 yönetici, katılımcı ilgisiz (Laissez-Faire) liderlik yaklaşımının olduğunu ifade etmiştir6 yönetici, katılımcı liderlik yerine yönetici kimliğinin ön plana çıktığını, 5 yönetici ise ise bu soruya cevap vermemiştir.

Genel olarak katılımcıların insan odaklı etkileşimci liderlik tarzlarını benimsedikleri görülmüştür. Aşağıda bu soruya ilişkin katılımcıların ortaya koyduğu cevap ve görüşlere örnekler verilmiştir.

\section{K: Kurumundaki liderlik, genelde insanlar yönetmek. üzere iletișim odaklidr.}

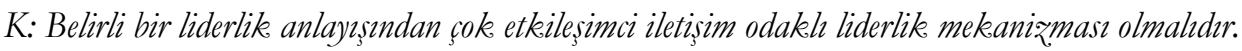

K: Sadece kurumumda değil tüm kurumlarda durum. Kişiye göre, kurumsallaşmamıs yönetim (liderlike) tarz̨ 


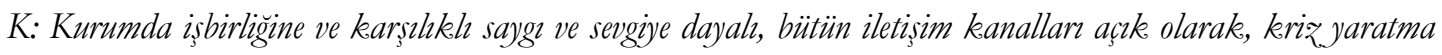

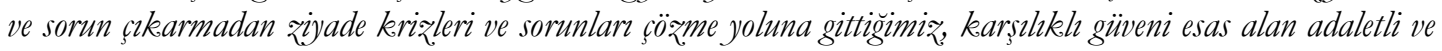
birey eksenli bir lider anlayışı bâkimdir.
\end{abstract}

\title{
K:Kurumumuzda iletişim odaklh liderlik anlayış vardir. Lider yönetici birbirinden tamamen farkhdir. Lider inovasyon becerisi yüksektir, yaraticudr.
}

\section{Tartışma, Sonuç ve Öneriler}

Çalışma kapsamında elde edilen sonuçlar, özel ve kamu sektöründe çalışan yöneticilerinin kuantum liderlik algılarının yüksek düzeyde olduğunu ve kuantum liderlik yaklaşımını önemsediklerini göstermiştir. Katılımcılara göre liderler kurumlarında ortak bir vizyon oluşturacak güce sahip olmalı, örgüt kültürünü zenginleştirmek ve kuvvetlendirmek için çalışmalı, diğer çalşanlarla iş birliği yapmalı, örgüt üyelerinin iyi ilişkileriyle desteklemeli, iş ve süreçler hakkında onları yüreklendirmeli, belirsizlik, kriz ve kaos durumlarında durumunda korkmadan karar verebilmeli ve inisiyatif alabilmelidir. Genel olarak araştırmaya katılan yöneticilerin kuantum liderlik algılarının özel ve kamu sektöründe yüksek ve olumlu yönde olduğu görülmüştür. Ayrıca katılımcıların cinsiyet ve çalıştıkları kurum türüne göre (özel-devlet) kuantum liderlik algılarının benzer düzeyde olduğu anlaşılmıştır. Bununla birlikte görüşme formundaki ifadeler incelendiğinde, yöneticilerin mesleki kıdemi arttıkça kuantum liderlik algılarının belirginleştiği görülmüştür. Her iki sektörde de yaş, çalışma ve yöneticilik görev süreleri arttıkça kuantum liderlik algı düzeyleri de artış göstermektedir.

Mitonga-Monga ve Coetzee'e (2012, s. 2) göre yöneticilerin liderlik tarz1, liderlerin astlarıyla etkileşimde bulunmak için kullandıkları farklı özelliklerin ve davranışların bir kombinasyonu olarak görülür. Liderlik sebep sonuç ilişkisiyle açıklanabilen etkisi kişisel güce ve etkin iletişime dayanan bir süreçtir. Bu kapsamda yöneticilere görüşme formunda yer alan; lider kurumda diğer çalışanlarla iş birliği yapmak ve örgüte sahip çıkmak zorundadır, lider örgüt üyelerinin açık iletişimini destekleyecek uygulamalar yürütmelidir, Lider örgüt üyelerinin iyi ilişkilerini desteklemelidir şeklinde ki ifadeleri destekler cevaplar verdikleri görülmüştür.

Lider örgütün başarısı için ortak çalışma ve iş birliği kapsamında örgüt ikliminin oluşmasından sorumludur. Klein ve arkadaşlarına (2013, s. 241) göre liderlik tarzı, örgüt kültürü ve iklimiyle yakından ilişskilidir. Bu bağlamda görüşme formunda yer alan sorulardan, Lider kurumda ortak bir vizyon oluşturacak güce sahip olmalıdır, lider kurumda örgüt kültürünü zenginleştirmek ve kuvvetlendirmek için çalışmalıdır, lider örgüt üyelerini iş ve süreçler hakkında yüreklendirmeli ve desteklemelidir, lider örgüt çalışanlarını yetiştiren ve kişi merkezli bir örgüt geliştirmek için çalışmalıdır ifadelerinin tamamının katılımcıların tarafından desteklenmesi araştırma katılımcılarının kuantum liderlik konusundaki algılama düzeylerinin kuantum liderlik yaklaşımıyla örtüştüğü görülmektedir.

Araştırmanın nitel bulgularına göre özel ve kamu üst düzey yöneticilerin "yönetim ve liderlik konusundaki eğitimlere yoğun bir katılım gösterdikleri görülmüştür. Bu kapsamda katılımcıların eğitimlere, liderlik eğitimi programlarına, gelişim programlarına, yöneticilik eğitimlerine, üniversite konferans ve seminerleri, şirket içi çalışmalar ve toplantılara kapsamındaki liderlik programlarına katıldıkları görülmüştür.

Araştırmada katılımcıların çok azının liderlik kavramını bilimsel ve teknik terminolojiye göre tanımladığı buna karşın çoğunun ise kısa anonim hale gelmiş özdeyişlerle kendi kişisel görüşlerine göre bir liderlik tanımlaması yaptığı görülmüştür. Bununla birlikte katılımcının liderliği yöneticilik kavramıyla ilişkilendirerek tanımlaması dikkat çekicidir.

Araştırmanın nitel boyutunda son olarak katılımciların kurumlarında ki liderlik anlayışını tanımlamaları istenmiştir. Nitel analizlere göre katıllımcılar kurumlarında kaotik-belirsiz, liderlik yerine belirsizlik durumlarında kuantum liderlik ve etkileşimli bir liderlik anlayışının ön plana çıktığını ifade etmişlerdir.

Katılımcıların ifadelerinden kurumlarında liderlerin çoğu zaman niteliklerine veya uzmanlıklarına göre değil, kurallara uyma ve bunları yerine getirme yeteneklerinden dolayı pozisyonlarına ulaştıkları vurgusu yapılmıştır. Araştırmada katılımcıların çoğu kurumlarında insan odaklı ve etkileşimli bir liderlik yaklaşımına ilişkin açıklamalarda bulunmuşlardır. Iqbal, Anwar ve Haider'a göre $(2015$, s. 1) insan odaklı liderlik ile liderler, insanları organize etmeye, desteklemeye ve geliştirmeye odaklanmışıı. Bu katıllımcı yaklaşım organizasyonlarda takım çalışması ve işbirliğini teşvik etmektedir. İnsan odaklı liderler organizasyondaki tüm çalışanlara eşit ve adil davranmakta, çalsşanların ihtiyaç duymaları halinde hemen etkileşime 
girebilmektedirler. Bu yönüyle insan odaklı liderliğin baskın olduğu örgütlerde çalışan motivasyonu ve süreçlere katılımı yüksek düzeydedir.

$\mathrm{Bu}$ çalışma üst düzey yöneticilerin kuantum liderlik yaklaşımı algılarını liderlik ve yöneticilik özelliklerine ilişkin görüş, olgu ve beklentilerini ortaya koymaya odaklanmıştır. Ortaya çıkan bulgular, yöneticilerinin kurumlarında kuantum liderlik davranışlarını olumlu yönde geliştirmeye yönelik beklentilerinin güçlü olduğunu ortaya çıkarmıştır. Bu kapsamda farklı örgütlerde yöneticilerin kuantum liderlik algılarını ve davranışlarını ortaya çıartılabilecek özellikle belirsizlik durumlarında gerekli Kuantum liderlik yaklaşımlarının belirlenebilmesi için özel sektör genelinde ölçek geliştirme çalısmaları gerçekleştirilebilir. oluşturulabilir. Araştırmacılar açısından farklı sektörlerde, yöneticilerin kuantum liderlik davranışlarını gözlemlemeyi sağlayan eylem araştırmalarının yanı sıra, kuantum liderlik davranışlarının çalışanlar üzerindeki etkilerine yönelik çok değişsenli araştırmalar yapılabilir.

\section{Etik Beyan}

"Yöneticilerin Kuantum Liderlik Algılarının İncelenmesi Üzerine Nitel Bir Araştırma" başlıklı çalışmanın yazım sürecinde bilimsel, etik ve alıntı kurallarına uyulmuş; toplanan veriler üzerinde herhangi bir tahrifat yapılmamış ve bu çalışma herhangi başka bir akademik yayın ortamına değerlendirme için gönderilmemiştir.

\section{Kaynakça}

Clark, V. L. P. ve Creswell, J. W. (2014). Understanding research: A consumer's guide. Boston: MA: Pearson Education Inc. Creswell, J. W. (2003). Research design: Qualitative, quantitative, and mixed methods approaches. Thousand oaks, CA: Sage.

Erçetin, Ş. Ş., Çevik, M. S. ve Çelik, M.(2018). Okul müdürlerinin kuantum liderlik davranışlarını gerçekleştirme düzeyleri. Uluslararası Liderlik. Callsmalar Dergisi, 1(2), 109-124.

Erçetin, S. S. S. (2000). Lider sarmalinda viąyon. Ankara: Nobel Yayınclik.

Erçetin, S. S.. ve Kamac1, M. C.(2008). Quantum leadership paradigm. World Applied Sciences Joural, 3(6), 865-868.

Ertürk Kayman, E. A. (2008). Türkiye'deki mesleki eğitim ve ögrretimin güglendirilmesi projesi (megep) içindeki yaygenlasstrnc okul yöneticilerinin, kuantum liderlik davranşlarm gerçekelestirme düreyleri (Yüksek Lisans Tezi). Hacettepe Üniversitesi Sosyal Bilimler Enstitüsü, Ankara.

Ertürk, A. (2016). Çağdaş liderlik yaklaşımları: Hizmetkâr liderlik - ruhsal liderlik - kuantum liderlik. İçinde N. Güçlü (Edt.), Eğitim yönetiminde liderlik: Teori arasturma, uygulama (ss. 133-168). Ankara: Pegem Akademi.

Fris, J. ve Lazaridou, A. (2006). An additional way of thinking about organizational life and leadership: The quantum perspective. Canadian Journal of Educational Administration and Policy, 48(5), 1-29.

Iqbal, N., Anwar., S. ve Haider, N. (2015). Effect of leadership style on employee performance. Arabian Journal of Business and Management Review, 5(5),1-6.

Jacobs, R. (1994). Using real time strategic change: How to involve an entire organization in fast and far reacbing change. San Francisco: Berrett-Koehle.

Khajeh, H. K. I. (2018). Impact of leadership styles on organizational performance. Journal of Human Resources Management Research, 2, 5-13.

Kilmann, R. H. (2011). Quantom organizations: A new paradigm for acbieving organizational success and personal meaning. Newport Coast, CA: Kilmann Diagnostics.

Mitonga-Monga, J. ve Coetzee, M. (2012). Perceived leadership style and employee participation. African Journal of Business Management, 6(15), 2-13

Morrison, K. (2002). School leadership and complexity theory. London: Routledge Falmer.

Owen, H. (1997). Expanding our now: The story of open space technology. San Francisco: Berrett-Kochler Publishers.

Quigley, M. E.(1997). Quantum organization. Executive Excellence, 14(5), 14-15.

Rose, C. ve Nicholl, M. (1997). Accelerated learning for the 21st century: The six-step plan to unlock your master-mind. New York: Delacorte.

Shelton, C. (2011). Quantum leaps: Seven skills for work place recreation. New York: Routledge.

Sougui, A. O., Bon, A. T. B. ve Hassan, H. M. H.(2015.) The impact of leadership styles on employees' performance in telecom engineering companies. International Conference on Tourism and Hospitality.

Treicher, M. ve Carmichael, F. (2004). In the organization of the future, competitive advantage will lie with inspired employees. Research-Technology Management, 42(4), 2-7.

Turan, S., ve Erçetin, Ş. Ş. (2017). Okul yöneticilerinin kuantum liderlik davranışlarının örgütsel zeka düzeyine etkisi. Turkish Studies, 12(6), 761-782.

Uzunçarşıll, Ü., Toprak, M. ve Ersun, O. (2000). Şirket kültuirü ve iş prensipleri. İstanbul: İstanbul Ticaret Odası Yayını.

Yıldırım, A. ve Şimşek, H. (2005). Sosyal bilimlerde nitel araştırma yöntemleri. Ankara: Seçkin Yayıncilık.

Yıldırım, A., ve Şimşek, H. (2011). Sosyal bilimlerde nitel araştırma yöntemleri. Ankara: Seçkin Yayıncılık.

Youngblood, M. D. (1997). Leadership at the of chaos: from control to creativity. Strategy Leadership, 25(5), 8-14.

Zohar, D. (1991). The quantum self: Human nature and consciousness defined by the new physics. Newyork: Quill William Morrow. 


\section{EXTENDED ABSTRACT}

In today's management approach, organizations are complex structures that function as dynamic systems. In management, the Quantum view considers an organization and its members as energetic, interdependent entities reinforced by co-operation and interaction. These linkages are not linear and hierarchical. Quantum perspective in organizations emphasizes free-flow interaction; the internal dynamics of the organization affects all members of the organization. The quantum perspective clearly shows that the only meaningful change in organizations comes from within and emerges among the various members. In this context, leadership approaches are needed in organizations in order to make a positive difference in the life of the members and the society. The quantum leadership approach includes approaches to making informed decisions by establishing strong relationships with two-way open communication that nurtures both individuals and organizations in line with the determined vision, mission and goals, and by acquiring information by listening to members and strengthening them. Quantum leadership is an approach that directs the organization to the future and leads the organization to its goals. Productivity in the future is extremely important for ensuring performance, profitability and competitive advantage (Kilmaneen, 2001, p. 42). Quantum leadership is not an organizational task, but a process that allows all employees to join the organization. In quantum organizations, leaders delegate their power to affiliated employees and bring it to the next level (Jacobs, 1994, p. 4). When leaders use quantum awareness, they want to build a structure that promotes continuous learning to develop careful decisionmaking through intuitive process (Rose and Nicholl, 1997, p. 62). Leaders use quantum leadership skills to plan theirs and organizational goals. Using this skill by leaders enables them to be responsible for choosing courtesy, compassion and honesty (Zohar, 1991, p. 51). Using quantum skills is a very difficult process because of the traditional structures in the traditional organization. Quantum leadership creates many new organizational processes and greatly simplifies the employee's contribution to organizational goals (Owen, 1997,s. 23). To implement quantum abilities in their organizations, leaders should create a new environment where employees can communicate with each other and with their horizontal and vertical organizational structure without any restrictions (Kilmann, 2011, p. 41).

The aim of this study is to determine the quantum leadership behaviors of senior executives working in the private and public sectors. In order to formulate research questions and to determine the characteristics of the quantum leadership approach and the skills that managers should have, a field study was conducted. On the purpose of determining whether the managers have quantum leadership skills, they are asked questions in a semi-structured questionnaire. The participants of the study are senior executives working in the private and state sectors in the province of Kars. In this research, review of literature is performed and a semi-structured interview form consisting of 14 questions is used as a data collection method. Also four questions are asked to carry out open-ended content analysis. The questions in the interview form have been prepared by taking into consideration the features required by the quantum leadership approach. The answers of the senior executives to the interview questions have been evaluated by using the content analysis method. According to the findings of the study, it has been seen that the participant managers' perceptions of quantum leadership is high, positive and important. Participants' perceptions of quantum leadership are similar in terms of gender and the type of institution (private-state) they work in. In addition to this, as professional seniority increases, participants consider quantum leadership more important. According to the qualitative findings of the study, it has been observed that the participants attend intensely training programs of leadership and management. In this context, it is seen that participants participate in leadership training programs, development programs, management trainings, university conferences and seminars. According to the qualitative findings of the study, it is seen that very few of the participants define the concept of leadership in accordance with the scientific and technical terminology, whereas most of them have a definition of leadership according to their personal views with short anonymized aphorisms. The participants bring the managerial concept and bureaucratic leadership style into forefront instead of leadership in their institutions. However, it can be mentioned that there is a practice in an interactive leadership style in very few institutions. $n$ the statements of the participants, it was emphasized that the leaders in their institutions often reached their positions not because of their qualifications or expertise, but because of their ability to obey and fulfill the rules. In the study, a few of the participants made explanations about a human-oriented and interactive leadership style in their institutions. According to Iqbal, Anwar and Haider (2015, p. 1), people-oriented leadership and leaders focused on organizing, supporting and developing people in their teams. It is a participatory style and tends to promote good teamwork and creative collaboration. People-oriented leaders treat everyone on the team equally. They are friendly and approachable, paying attention to the 
well-being of everyone in the group and making them accessible when team members need help or advice. In this respect, the motivation and participation of employees in organizations dominated by peopleoriented leadership is high.

This study focuses on revealing the opinions, facts and expectations of leadership and managerial characteristics of senior managers on the basis of quantum leadership style. The findings revealed that managers have strong expectations for positive development of leadership styles in their institutions. In this context, action plans can be developed and strategic goals can be determined in order to develop the leadership styles and skills of managers in different organizations. For researchers, they can conduct action research in different organizations, which allows managers to observe situations in which they can develop leadership styles within the framework of an effective organizational culture. They can also conduct multivariate research on the effects of quantum leadership behaviors on employees. 